\section{Explicit motor learning interventions are still relevant for $A C L$ injury rehabilitation: do not put all your eggs in the implicit basket!}

\author{
Elmar Kal $\odot,{ }^{1,2}$ Toby Ellmers, ${ }^{2,3}$ Jed Diekfuss, ${ }^{4,5}$ Marinus Winters $\odot,{ }^{6}$ \\ John van der Kamp ${ }^{7,8}$
}

\section{INTRODUCTION}

ACL ruptures are rapidly increasing. ${ }^{1}$ ACL injuries can have a profound impact on an athlete's physical and psychological functioning, and sporting career. Current standard of care following ACL injury is neuromuscular rehabilitation to help athletes regain motor skills. Optimising how rehabilitation is delivered has the potential to further enhance motor relearning and reduce the risk of secondary knee injuries. ${ }^{2}$

ACL injury rehabilitation programmes aiming to reduce secondary injury risk often involve explicit learning strategies to improve biomechanics and increase neuromuscular control. ${ }^{3}$ Athletes are mostly instructed to consciously control movements using internally focused, verbal cues that prescribe desired movement patterns (eg, 'do not bring your knees over your toes' during squatting). Only with sustained practice does explicit learning result in consistent, fluent, and automatic, motor performance.

Recently, practitioners have been encouraged to minimise explicit learning

${ }^{1}$ College of Health, Medicine and Life Sciences; Department of Health Sciences, Brunel University London, London, UK

${ }^{2}$ College of Health, Medicine and Life Sciences; Centre for Cognitive Neuroscience, Brunel University London, London, UK

${ }^{3}$ School of Sport and Health Sciences, University of Exeter, Exeter, UK

${ }^{4}$ The SPORT Center, Division of Sports Medicine, Cincinnati Children's Hospital Medical Center, Cincinnati, Ohio, USA

${ }^{5}$ Department of Orthopaedics, Emory University School of Medicine, Atlanta, Georgia, USA

${ }^{6}$ Research Unit for General Practice in Aalborg, Department of Clinical Medicine, Aalborg University Faculty of Health Sciences, Aalborg, Denmark ${ }^{7}$ Department of Human Movement Sciences, Faculty of Behavioural and Movement Sciences, Vrije Universiteit Amsterdam, Amsterdam, The Netherlands

${ }^{8}$ Research Centre for Exercise, School and Sport, Windesheim University of Applied Sciences, Zwolle, The Netherlands

Correspondence to Dr Elmar Kal, College of Health, Medicine and Life Sciences; Department of Health Sciences, Brunel University London, London UB8 3PH, UK; elmar.kal@brunel.ac.uk during ACL injury rehabilitation, and use implicit learning interventions such as external focus cues. ${ }^{2}$ We contend that implicit interventions are not a panacea, and that explicit interventions remain important in ACL injury rehabilitation. We discuss key individual characteristics and contextual constraints that warrant the use of explicit interventions.

Why would implicit learning be beneficial to ACL rehabilitation?

The theoretical advantage of implicit learning interventions is that athletes reach automaticity earlier in the learning process. Accordingly, implicit learning should reduce the risk of reinjury as:

- Athletes will have more attentional resources available to deal with high cognitive-perceptual demands of events that often precipitate ACL injuries (eg, an approaching defender or incoming ball).

- Athletes will be less likely to fall back on using verbal rules to consciously control movement, especially when anxious or fatigued. This enables them to 'self-organise' and flexibly adapt to quickly changing task demands (eg, a rapid change in direction of movement).

Evidence for implicit learning in the context of ACL injury

There is evidence that interventions that aim to induce implicit learning can improve preliminary outcomes associated with ACL injury risk (eg, knee biomechanics in standardised laboratory tasks). ${ }^{4}$ However, changes in biomechanics may not readily translate to actual changes in injury risk. It is also unclear whether improved biomechanics can be attributed to implicit learning per se, as researchers generally do not provide evidence to confirm whether implicit learning indeed occurred (eg, through self-report). For example, Welling et $a l^{4}$ attributed positive effects of a video-instruction intervention on jump landing technique to implicit learning. However, participants almost exclusively reported to have focused internally on movement technique-suggesting explicit learning had occurred.

Moreover, the effects of a purely implicit or explicit ACL injury rehabilitation programme on actual secondary knee injury incidence rates have never been examined. Explicit verbal feedback on movement has, however, been identified as a key active ingredient in primary ACL injury risk reduction. ${ }^{5}$

It may be best to hedge our bets and avoid putting all our money on implicit learning strategies in the ACL rehabilitation context!

\section{Reappraising explicit motor learning \\ Tailoring to the individual}

Individual differences in proprioception, working memory and motor learning preferences could influence the effectiveness of prescribing implicit or explicit learning interventions for ACL injury rehabilitation (see table 1$)^{6-9}$ :

- Proprioceptive deficits are common following ACL injury. ${ }^{10}$ Proprioception is key to effective automatic movement control, ${ }^{6}$ and people with proprioceptive deficits benefit from explicit, rather than implicit, motor learning interventions. ${ }^{7}$

- Explicit learning is a cognitively demanding learning method. An individual needs to be able to process verbal instructions, keep these in mind and use these to guide movement execution. There is evidence that individuals with greater verbal working memory capacity benefit from explicit learning. Implicit learning seems more beneficial for individuals with poorer verbal working memory capacity. ${ }^{8}$

- Implicit or explicit learning appears most effective when it is aligned with an individual's preference. ${ }^{9}$

While not yet tested in the context of ACL rehabilitation, the above findings strongly warrant against an isolated, one-size-fits-all approach to motor learning. Screening these factors (table 1) may help guide decisionmaking for the prescription of implicit and explicit motor learning interventions during ACL injury rehabilitation.

\section{Explicit learning strategies to correct} suboptimal movement patterns

Context in which athletes perform after ACL injury is also important. Explicit control is necessary for high-level, complex motor performance in cognitively demanding scenarios ${ }^{11}$ - those in which 
Table 1 Individual constraints that could influence effectiveness of implicit and explicit motor learning interventions

\begin{tabular}{|c|c|c|c|}
\hline & Individual factor & & \\
\hline & Proprioception & Verbal working memory & Athlete's preference \\
\hline Relevance in $\mathrm{ACL}$ rehabilitation & $\begin{array}{l}\text { ACL serves role in proprioception } \\
\text { High prevalence of proprioceptive } \\
\text { impairment following } \mathrm{ACL} \text { injury }\end{array}$ & $\begin{array}{l}\text { Capacity differs from person to person } \\
\text { High prevalence of ACL injury in young } \\
\text { athletes }^{52} \text {, for whom working memory } \\
\text { capacity is still developing }^{53}\end{array}$ & $\begin{array}{l}\text { Preference for explicit/implicit learning } \\
\text { differs from person to person } \\
\text { People with musculoskeletal conditions } \\
\text { strongly prefer to consciously control } \\
\text { movements }^{54.5}\end{array}$ \\
\hline Role in motor learning & $\begin{array}{l}\text { Proprioceptive deficits compromise } \\
\text { automatic movement control } \\
\text { Individuals with deficits benefit from } \\
\text { explicit learning } \\
58-10\end{array}$ & $\begin{array}{l}\text { Verbal working memory is key to process } \\
\text { explicit movement instructions }{ }^{511} \\
\text { Individuals with lower working memory } \\
\text { capacity benefit from implicit learning }\end{array}$ & $\begin{array}{l}\text { Individuals benefit from learning } \\
\text { interventions that match their preference, } \\
\text { for example, explicit strategies benefit } \\
\text { those who prefer conscious control }{ }^{514.15}\end{array}$ \\
\hline Clinical recommendation & $\begin{array}{l}\text { Consider more frequently using explicit } \\
\text { learning interventions in case of } \\
\text { proprioceptive deficits } \\
\text { Screen proprioceptive deficits in both } \\
\text { the affected and unaffected knee, using } \\
\text { Joint-Position Sense tests }\end{array}$ & $\begin{array}{l}\text { Consider more frequently using implicit } \\
\text { learning interventions for athletes with poor } \\
\text { verbal working memory } \\
\text { Screen for verbal working memory deficits, } \\
\text { for example, using Trail-Making Test } \mathrm{B}^{\mathrm{S16}} \text { or } \\
\text { Automated Operation Span Test }{ }^{517}\end{array}$ & $\begin{array}{l}\text { Consider more frequently using motor } \\
\text { learning method that aligns with athlete's } \\
\text { preference } \\
\text { Screen preference for conscious control } \\
\text { using Movement-Specific Reinvestment } \\
\text { Scale }\end{array}$ \\
\hline
\end{tabular}

References contained in this table can be found in the 'online supplemental files'.

most non-contact ACL injuries occur. Explicit control allows the performer to intentionally correct inappropriate automatic motor responses, making small changes to technique as required. ${ }^{11}$ Elite athletes have shown to successfully use explicit interventions to de-automate, and subsequently improve, problematic movements. ${ }^{11}$ We therefore recommend caution against eradicating explicit motor learning interventions from ACL rehabilitation.

\section{CONCLUSION}

Motor learning to regain sports-specific motor skills after ACL injury is not a 'onesize-fits-all' exercise. Coaches and healthcare practitioners need to blend implicit and explicit interventions, and tailor them according to personal and contextual factors. We argue that a blended approach has strong potential to improve outcomes of ACL injury rehabilitation.

Twitter Elmar Kal @elmar_kal and Marinus Winters @marinuswinters

Contributors EK wrote the first draft. TE, JD, MW and JvdK provided important intellectual input. All authors consented to the final version of the manuscript.

Funding The authors have not declared a specific grant for this research from any funding agency in the public, commercial or not-for-profit sectors.

Competing interests None declared.

Patient consent for publication Not required.

Provenance and peer review Not commissioned; externally peer reviewed.

Supplemental material This content has been supplied by the author(s). It has not been vetted by BMJ Publishing Group Limited (BMJ) and may not have been peer-reviewed. Any opinions or recommendations discussed are solely those of the author(s) and are not endorsed by BMJ. BMJ disclaims all liability and responsibility arising from any reliance placed on the content. Where the content includes any translated material, BMJ does not warrant the accuracy and reliability of the translations (including but not limited to local regulations, clinical guidelines, terminology, drug names and drug dosages), and is not responsible for any error and/or omissions arising from translation and adaptation or otherwise.

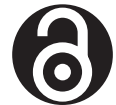

\section{OPEN ACCESS}

Open access This is an open access article distributed in accordance with the Creative Commons Attribution 4.0 Unported (CC BY 4.0) license, which permits others to copy, redistribute, remix, transform and build upon this work for any purpose, provided the original work is properly cited, a link to the licence is given, and indication of whether changes were made. See: https:// creativecommons.org/licenses/by/4.0/.

(c) Author(s) (or their employer(s)) 2021. Re-use permitted under CC BY. Published by BMJ.

- Additional material is published online only. To view, please visit the journal online (http://dx.doi.org/ 10.1136/bjsports-2020-103643).

\section{(A) Check for updates}

To cite Kal E, Ellmers T, Diekfuss J, et al. Br J Sports Med Epub ahead of print: [please include Day Month Year]. doi:10.1136/bjsports-2020-103643 Accepted 30 January 2021

Br J Sports Med 2021;0:1-2.

doi:10.1136/bjsports-2020-103643

\section{ORCID iDs}

Elmar Kal http://orcid.org/0000-0002-1481-3016

Marinus Winters http://orcid.org/0000-0001-57427441

\section{REFERENCES}

1 Abram SGF, Price AJ, Judge A, et al. Anterior cruciate ligament $(\mathrm{ACL})$ reconstruction and meniscal repair rates have both increased in the past 20 years in England: Hospital statistics from 1997 to 2017. Br J Sports Med 2020:54:286-91.

2 Benjaminse A, Holden S, Myer GD. ACL rupture is a single leg injury but a double leg problem: too much focus on 'symmetry' alone and that's not enough! Br J Sports Med 2018:52:1029-30.

3 Myer GD, Paterno MV, Ford KR, et al. Neuromuscular training techniques to target deficits before return to sport after anterior cruciate ligament reconstruction. J Strength Cond Res 2008:22:987-1014.

4 Welling W, Benjaminse A, Gokeler A, et al. Enhanced retention of drop vertical jump landing technique: a randomized controlled trial. Hum Mov Sci 2016:45:84-95.

5 Sugimoto D, Myer GD, Barber Foss KD, et al. Critical components of neuromuscular training to reduce $\mathrm{ACL}$ injury risk in female athletes: meta-regression analysis. Br J Sports Med 2016;50:1259-66.

6 Clark DJ. Automaticity of walking: functional significance, mechanisms, measurement and rehabilitation strategies. Front Hum Neurosci 2015:9:246

7 Ingram HA, van Donkelaar P, Cole J, et al. The role of proprioception and attention in a visuomotor adaptation task. Exp Brain Res 2000;132:114-26.

8 Buszard T, Farrow D, Verswijveren SJJM, et al. Working memory capacity limits motor learning when implementing multiple instructions. Front Psychol 2017:8:1350.

9 Maurer $\mathrm{H}$, Munzert J. Influence of attentional focus on skilled motor performance: performance decrement under unfamiliar focus conditions. Hum Mov Sci 2013;32:730-40.

10 Relph N, Herrington L, Tyson S. The effects of ACL injury on knee proprioception: a meta-analysis. Physiotherapy 2014;100:187-95.

11 Toner J, Moran A. Exploring the orthogonal relationship between controlled and automated processes in skilled action. Rev Philos Psychol 2020:1-17 